\title{
Correlação entre sismicidade e geologia em Caruaru (PE)
}

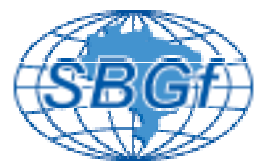

${ }^{1}$ Ferreira, J.M., ${ }^{2}$ Bezerra, F.H.R. , ${ }^{1}$ Oliveira, R.T. \& ${ }^{1}$ França, G.S., 1 - DFTE/CCET/UFRN; 2 - DG/CCET/UFRN

\section{Copyright 2004, SBGf - Sociedade Brasileira de Geofísica}

Este texto foi preparado para a apresentação no I Simpósio de Geofísica da Sociedade Brasileira de Geofísica, São Paulo, 26-28 de setembro de 2004. Seu conteúdo foi revisado pela Comissão Tecno-científica do I SR-SBGf mas não necessariamente representa a opinião da SBGf ou de seus associados. E proibida a reprodução total ou parcial deste material para propósitos comerciais sem prévia autorização da SBGt.

\section{Resumo}

A atividade sísmica na região de Caruaru (PE) é conhecida há mais de um século, tendo seu último surto ocorrido a partir de 2002. A partir de 1980 foram feitos diversos estudos, inicialmente com dados macrossísmicos, e, posteriormente com redes sismográficas portáteis, tendo, as principais campanhas, sido realizadas em 1991 e 2002. Ao longo desse tempo foi possível se formar uma idéia da localização das principais zonas ativas, determinar os mecanismos focais, e verificar a forte correlação entre a sismicidade, o regime de esforços e a geologia.

\section{Introdução}

A atividade sísmica na região de Caruaru é conhecida pela comunidade sismológica como tendo ocorrido a partir dos primeiros anos do século $\mathrm{XX}$ (Ferreira, 1983; Ferreira \& Assumpção, 1983). Informações mais recentes mostram que essa atividade vem sendo registrada desde meados do século XIX (UFRN, 2002).

Os principais eventos ocorreram em 1964 (dois eventos de magnitude 3,5 $\mathrm{m}_{\mathrm{b}}$ e intensidade $\left.\mathrm{V} M M\right), 1967$ (3,8 $\mathrm{m}_{\mathrm{b}}$ e V MM), 1984 (3,8 mb e V-VI MM) e 2002 (3,5 $m_{b}$ e V MM). Normalmente, como ocorre no Nordeste do Brasil, a atividade se dá na forma de enxame, cuja duração pode ser de diversos meses a anos, com um ou outro sismo de maior magnitude. Esse tipo de atividade é capaz de criar pânico na população, mesmo para magnitudes inferiores a 4,0 $\mathrm{m}_{\mathrm{b}}$, o que ocorreu em 1967, fazendo com que diversas pessoas abandonassem a região (Ferreira, 1983; Ferreira \& Assumpção, 1983).

Os sismos de 1967 e 1984 foram estudados a partir de dados macrossísmicos obtidos de jornais (1967) e de questionários macrossísmicos (1984). Dessa forma, foi possível determinar o epicentro macrossísmico desses eventos. Ambos foram registrados instrumentalmente e a magnitude dos mesmos foi determinada a partir desses registros.

Graças à intensa atividade sísmica ocorrida em João Câmara (RN), em 1986 (Ferreira et al., 1987) foi possível equipar o Laboratório Sismológico da UFRN com equipamento sismográfico portátil. Isso permitiu a realização de campanhas com redes sismográficas portáteis em diversas localidades do Nordeste do Brasil (Ferreira et al., 1998). As duas principais campanhas, levadas a cabo pela UFRN, na região de Caruaru foram realizadas em 1991 (Ferreira et al., 1998) e 2002 (UFRN, 2002). Assim, foi possível determinar os hipocentros e 0 mecanismo focal, relativos aos sismos registrados em cada campanha. A solução de mecanismo focal dos eventos de 1991 foi também utilizada na determinação das direções dos esforços máximos horizontais $\left(\mathrm{S}_{\mathrm{Hmax}}\right)$, no Nordeste do Brasil (Ferreira et al., 1998).

A atual atividade sísmica em Caruaru, iniciada em 2002, ainda está em andamento e está sendo monitorada por uma estação analógica e uma digital (com sismômetro triaxial tipo broad-band). O que torna a atividade sísmica em Caruaru extremamente relevante é que ocorre, ao longo do tempo, uma mudança na área epicentral, bem como uma mudança no estilo de falhamento. Apesar disso, como veremos adiante, há uma forte correlação entre a sismicidade, o regime de esforços e a geologia.

\section{Metodologia}

$\mathrm{Na}$ análise de dados macrossísmicos o ponto de partida é a descrição dos efeitos causados pelos tremores. A partir deles, com a ajuda de uma tabela de intensidades, no caso a Mercalli Modificada (MM; Wood \& Neumman, 1931), é possível determinar a intensidade do sismo em cada localidade, para as quais há informações. Dependendo da quantidade de dados é possível determinar a área onde o evento foi sentido (área afetada), traçar isossistas (linhas que delimitam regiões de igual intensidade), determinar 0 epicentro macrossísmico e estimar a magnitude, pela área afetada. O epicentro e a magnitude dos sismos históricos foram determinados dessa maneira (Ferreira \& Assumpção, 1983).

A melhor determinação dos parâmetros focais (hora de origem, epicentro, profundidade focal) é feita através da utilização de redes sismográficas portáteis sendo que a precisão dos resultados depende do número de estações utilizadas e da distribuição das mesmas. Na campanha de 1991 foram utilizadas até sete estações analógicas e na de 2002 foram utilizadas seis estações analógicas e uma digital. Os registros analógicos permitem uma precisão de leitura, com lupa micrométrica, de 0,025s e a estação digital de $0,001 \mathrm{~s}$.

A determinação dos hipocentros instrumentais foi feita utilizando-se o programa HYPO71 (Lee \& Lahr, 1975), num modelo de semi-espaco, com velocidade da onda $P$ 
(Vp) de $6,00 \mathrm{~km} / \mathrm{s}$ e razão entre as velocidades das ondas $\mathrm{P}$ e $\mathrm{S}(\mathrm{Vp} / \mathrm{Vs})$ igual a 1,73 . Devido ao pequeno número de estações utilizadas, além disso analógicas e somente com a componente vertical, foi determinado o mecanismo focal composto, utilizando-se o programa FPFIT (Reasenberg \& Oppenheimer, 1985), a partir das polaridades verticais da primeira chegada da onda $P$.

A determinação dos epicentros e do mecanismo focal são essenciais para a discussão da correlação entre a atividade sísmica e a geologia. Para tanto, foram comparados os resultados com dados geológicos préexistentes e feita uma viagem de campo às áreas epicentrais dos eventos de 1991 e 2002 tentando verificar, em superfície, feições relacionadas à atividade sísmica.

\section{Resultados}

Os epicentros dos sismos anteriores a 1984 não estão bem definidos, pois, praticamente só dados macrossísmicos eram disponíveis. O evento de 1967, de magnitude $3,8 \mathrm{mb}_{\mathrm{b}}$ foi registrado pela antiga estação de Natal (NAT) e seu epicentro provavelmente foi ao norte de Caruaru (Ferreira \& Assumpção, 1983). O sismo de 1984, também foi registrado por algumas estações regionais mas seu epicentro foi determinado a partir de um levantamento macrossísmico de detalhe, através da aplicação de questionários sísmicos entre a população e está localizado aproximadamente a $13 \mathrm{~km}$ a NE do centro da cidade (Figura1).

Na campanha de 1991, com sete estações sismográficas portáteis, a aglomeração principal de eventos estava a aproximadamente $7 \mathrm{~km}$ a oeste do centro da cidade de Caruaru mas foram também registrados alguns eventos esparsos, fora do aglomerado principal (Figura 1). Para a solução do mecanismo focal composto foram usados todos os sismos do aglomerado principal (Figura 2). Para uma visualização melhor de qual seria o plano de falha foram selecionados somente eventos com pelo menos 12 observações ( $P$ e $S)$, registradas pelo mesmo arranjo de estações. Para esses eventos verificou-se que a profundidade focal variava entre 3 e $5 \mathrm{~km}$. Dessa forma, foi possível determinar que mecanismo de falhamento era normal, com o plano de falha de direção aproximada EW e mergulho para o norte, submetida as esforços tracionais horizontais, de direção aproximada NS, e esforços horizontais compressivos, de direção aproximada EW.

Na campanha de 2002 foi utilizada uma rede de seis sismógrafos portáteis analógicos e um digital, durante cerca de quinze dias, em agosto de 2002, cerca de um mês e meio após a ocorrência do tremor de maior magnitude nesta reativação $\left(3,5 \mathrm{~m}_{\mathrm{b}}\right.$, no dia $\left.30 / 06\right)$. A zona epicentral está situada a aproximadamente $3,5 \mathrm{~km}$ a $\mathrm{NE}$ do centro da cidade (Figura 1). Os epicentros dos sismos ocorreram numa área pouco extensa (aproximadamente $1,2 \mathrm{~km}$ ) e numa faixa estreita de profundidades (entre 3,8 e 4,8 km). A análise da posição dos sismos melhor determinados, com erros na hora de origem, no epicentro e na profundidade, respectivamente $0,02 \mathrm{~s}, 0,2 \mathrm{~km}$ e $0,2 \mathrm{~km}$, permitiu identificar o plano de falha. Assim, o mecanismo é de uma falha dextral transcorrente, com pequena componente normal, de azimute de $232^{\circ}$, com mergulho de $70^{\circ}$ para NW, com os esforços horizontais compatíveis aos de 1991 (Figura 3).

Levantamentos geológicos preliminares foram feitos nas áreas epicentrais dos sismos de 1991 e 2002. Esses levantamentos mostraram que a orientação da falha sísmica a oeste (1991)coincide com a direção de zonas de ultramilonitos de espessura métrica a decimétrica, preenchidas por epidoto, indicando a reativação da foliação miloníticaem nível crustal intermediário.Diversas falhas de nível crustal raso e escala mesoscópica, dextrais e normais reativam estas zonas e coincidem com a atitude da falha sísmica. A falha sísmica a nordeste (2002) coincide com a orientação de zonas miloníticas, que sofrem inflexão para NE, a partir do lineamento de Pernambuco. Muitas falhas mesoscópicas e nível crustal raso reativam a foliação milonítica com a mesma atitude e cinemática da falha sísmica.

\section{Discussões e conclusões}

Embora não se saiba ao certo onde ocorreram as atividades sísmicas anteriores a 1984, é certo que a atividade sísmica em Caruaru vem se apresentando, com intensidade, em diferentes áreas sísmicas ao longo do tempo. Dessa forma, é possível que um monitoramento continuado da região venha a descobrir novas áreas de atividade, o que torna a região bastante interessante para estudos sismológicos e de neotectônica.

Em 1991 e 2002 foram feitas campanhas para o estudo da atividade sísmica em Caruaru com redes de estações sismográficas portáteis, em dois locais distintos. Embora o estilo do falhamento observado nas duas campanhas tenha sido diferente (normal, em 1991; transcorrente, em 2002), a direção das falhas também (EW, em 1991; NE, em 2002), ambas as atividades compatíveis com esforços horizontais compressivos EW e tracionais NS.

Grande parte das falhas mapeadas, no Nordeste do Brasil, são do período Pré-cambriano e, de fato, a correlação entre a sismicidade e essas falhas, é bastante difícil de comprovar, nas várias áreas do Nordeste onde foi possível a determinação de mecanismos focais. Recentemente novos estudos geológicos vêm sendo realizados pelo DG/UFRN, usando técnicas de Neotectônica, que podem esclarecer melhor esse problema. Apesar de tudo, em nenhuma das áreas epicentrais encontraram-se zonas de falhas que correspondam às rupturas mapeadas sismologicamente. Isto sugere que ambas as falhas são cegas. No entanto, um grande número de feições mesoscópicas mostram uma identidade entre os processos rúpteis em profundidade e na superfície. Dessa forma, podemos considerar que a sismicidade estudada em 1991 e 2002 representam reativações sísmicas do Lineamento de Pernambuco e sua ramificação NE. 


\section{Agradecimentos}

À Prefeitura Municipal de Caruaru, pelo apoio dado à campanha de 2002. Aos técnicos Eduardo Alexandre Santos de Menezes e Carlos Alberto dos Anjos, pelo trabalho de campo, análise e leitura dos sismogramas.

\section{Referências}

Ferreira, J.M., 1983. Sismicidade do Nordeste do Brasil. Tese de Mestrado, IAG/USP, 192 pp.

Ferreira, J.M. \& M. Assumpção, 1983. Sismicidade do Nordeste do Brasil. Rev. Bras. Geofis., 1: 67-88.

Ferreira, J.M. et al., 1987. A continuing intraplate earthquake sequence near João Câmara - Northeastern Brazil - preliminary results. Geophys. Res. Lett., 14: 14021405.

Ferreira, J.M., R.T. Oliveira, M.K. Takeya \& M. Assumpção, 1998. Superposition of local and regional stresses in Northeast Brazil: evidence from the Potiguar marginal basin. Geophys. J. Int., 134: 341-355.

Lee, W.H.K. \& J.C. Lahar, 1975. HYPO71 (revised): a computer program for determining hypocenter, magnitude, and first motion pattern of local earthquake. U.S. Geol. Surv. Open File Rep. 75-311, 114 pp.

Reasenberg, P. \& D. Oppenheimer, 1985. FPFIT, FPLOT and FPPAGE: Fortran computer programs for calculating and displaying earthquake fault-plane solutions. U.S. Geol. Surv. Open File Rep. 85-739, 109 pp.

UFRN, 2002. Atividade sísmica em Caruaru em 2002. Relatório final, LabSis/UFRN, 40 pp.

Wood H.O. \& F. Neumman, 1931. Modified Mercalli intensity scale of 1931. Bull. Seism. Soc. Am., 21: 277283.

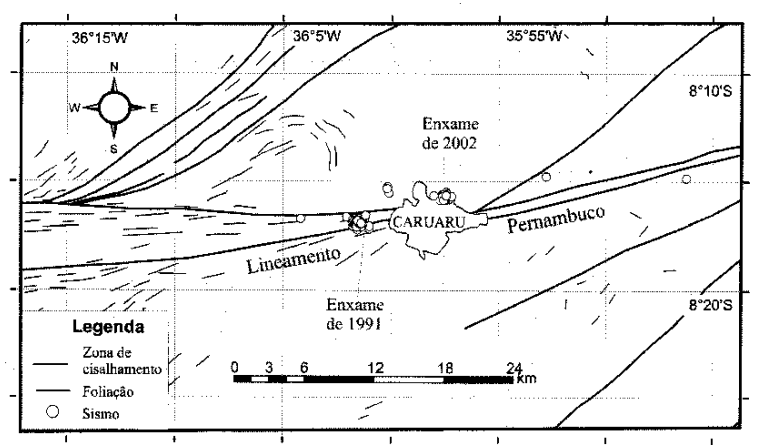

Figura 1

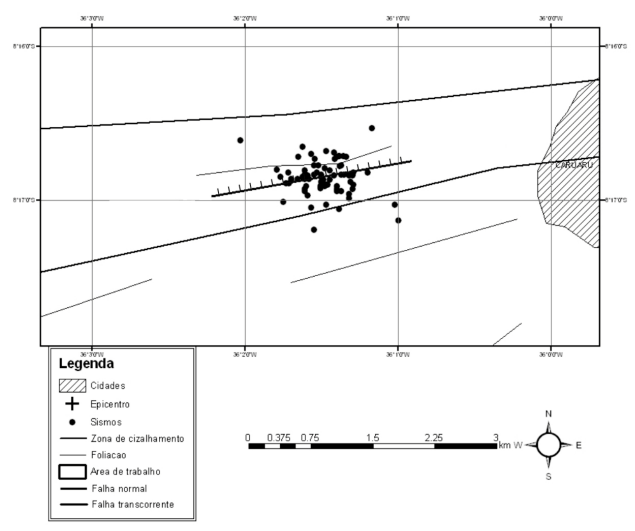

Figura 1

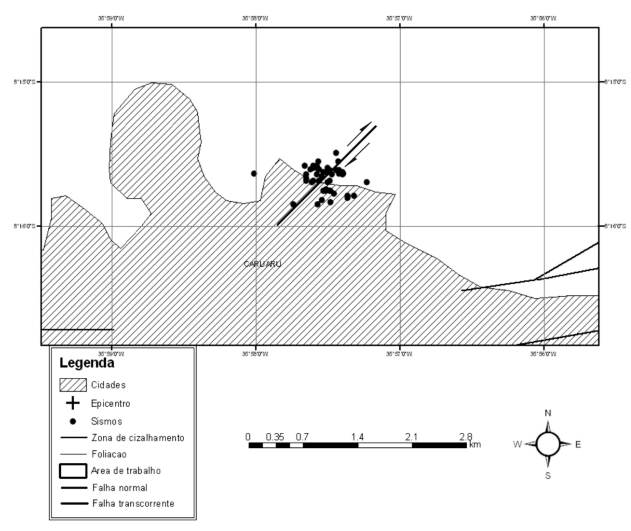

Figura 3 